\title{
Assessment of Factors Causing Student Satisfaction upon Service Delivery in the Newish Universities in Sri Lanka
}

\author{
WIJESIRI B M \\ Department of Business Management \\ Faculty of Business Studies \& Finance \\ Wayamba University of Sri Lanka \\ Kuliyapitiya \\ SRI LANKA \\ basnayakew@yahoo.com
}

\begin{abstract}
:-
This study attempted to examine relationship between service quality dimensions and satisfaction among students in newish universities in Sri Lanka. Furthermore, this study also examined the critical factors in service quality dimensions that contribute most to the satisfaction of the students. This study was conducted among 260 Bachelor's Degree students from three newly established universities using a set of questionnaire. The findings indicated that the majority of students are dissatisfied with the services provided by newly established universities. Further, the results indicated that all the five dimensions of service delivery were correlated with student satisfaction.
\end{abstract}

Keywords:-Student satisfaction, Service delivery, Newish Universities.

\section{Introduction \\ 1.1 Background}

Customer satisfaction is a vital aspect for service organization and specially, it is highly related to service quality. Higher Education (HE) is an extremely fast growing service industry. It is exposed to the globalization process every day more and more. Service quality, emphasizing student satisfaction, is a newly-emerging field of concern, in order to attract students, serves their needs and retains them. HE providers are actively involved in the process of understanding students' expectations and their perceptions of service quality. They have often to adopt techniques of measuring service quality of their services just like in the business sector. This study attempts to explore the aspects of service quality and the level of satisfaction among the students in the newly established universities in Sri Lanka.

\subsection{Problem Statement}

The universities are committed towards becoming world class universities. The major concerns and attribute that cannot be compromised is the issue of quality. Based on the university philosophy, vision, mission and long term goals, it is clear that the universities are consistently positive towards the quality education and appeared to be very dynamic in the quality approach and its technique. It can be observed that the effort made by all the university staffs in fulfilling and committing to the requirements and standards of the Quality Assurance imposed by the Quality Assurance and Accreditation Council of Sri Lanka. 
One of the major components highlighted in Quality Assurance Programme are meeting customer requirements and satisfactions. According to Berry and Parasuraman (1992), they argue that the strategic success of a service organization depends on the ability of service providers to enhance their images by consistently meeting or exceeding customers' service expectation. These components must be measured to response to the changes of the environment where the expectation of the stakeholders is becoming higher. The outcomes of the measurement are very useful for the university administrators as well as the academic staffs to provide plans and solutions for the continuous improvement so that service and the programmes offered by the universities are significant to the students.

The quality of university education in Sri Lanka is perceived to be unsatisfactory in the public discourse and the media. There are no solid data to document such perception in particular. It has been evident that demand for the public sector universities is very high. However, it was found that graduate outputs of those universities are not satisfied the service delivered by those universities. So, there is a huge gap between expectations of students and service delivered by the universities.

Then, this study is focused as the research problem, why the students are not satisfied with services delivered by the newish universities in Sri Lanka".

\subsection{Research Question}

This study is attempted to address the following questions:

(a) What relationship if any, exist between service quality dimensions and satisfaction among students in newish universities in Sri Lanka? (b) What are the critical factors in service quality dimensions that contribute most to the satisfaction of the students?

\section{$1.4 \quad$ Research Objectives}

Having considered the research questions stated above, and also the significance of the present research, the following objectives were determined.

(a) To study different perspectives of the service quality dimensions and to identify possible factors those have been influenced to the service quality operations in newish universities in Sri Lanka.

(b) To analyze those factors that have been influenced the service quality dimensions and service operations in the newish universities in Sri Lanka

(c) To identify the key quality dimensions that leads to student satisfaction.

\subsection{Significance of the Study}

This study is important because it is going to measure the level of service quality and the level of satisfaction among the students. The results from the study can be used to give valuable information on the elements and the dimensions, which have been given a priority by students assessing the quality of services and satisfaction.

\section{Literature Review 2.1 Service Quality}

Quality in higher learning institutions can be felt under service quality dimensions because of its characteristics. According to Dotchin and Oakland (1994); Zimmerman and Enell (1988), viewing higher education as a service can generalize service quality dimension for this sector. Service quality has been classified into multi-dimensional view 
such as Gronroos (1978); Lehtinen and Lehtinen (1992); Parasuraman et al. (1985). According to Parasuranman et al. (1985) service quality dimensions that used in the higher education are as follows and has modified by Ghobadian et al. (1994) in their research; Reliability, Responsiveness, Customization, Credibility, Competence, Access, Courtesy, Security, Communication, Tangibles, and Understanding customers. Services quality dimension proposed by Gronroos (1978) has three dimensions; "the technical quality of outcome", "the functional quality of the service encounter" and "the corporate image".

Lehtinen and Lehtinen (1992) also proposed three dimensions of service quality. According to their study, the dimensions are as (a) Physical quality, (b) Corporate quality and (c) Interactive quality

\subsection{Student Satisfaction}

According to Kotler and Clarke (1987), satisfaction is a state felt by a person who has experienced performance or an outcome that fulfil his or her expectation. Conceptually satisfaction is an outcome of purchase and use resulting from the buyer's comparison of the rewards and costs of the purchase in relation to the anticipated consequences. Operationally, satisfaction is similar to attitude in that it can be assessed as the sum of the satisfactions with the various attributes of the product or service.

Satisfaction is related closely to, but is not the same as the customer's general attitude toward the service. The key to distinguishing satisfaction from attitude is that satisfaction assessments relate to individual transaction whereas attitudes are more general. Parasuraman, Zeithmal, and Berry (1988), defines perceived (Service) quality as the consumer's judgment about a firm's overall excellence or superiority. This definition suggests that perceived quality is similar to an individual's general attitude toward the organization.

\subsection{Service Quality in Higher Education}

According to the study by Cuthbert (1996), it has been found that among the dimension in Service Quality, the score for tangibility (3.34) is the highest, followed by assurance (3.21), reliable (3.11), responsive (3.04) and empathy (2.58). However, he added that this does not represent tangibility as a major contributor towards satisfaction of the students as he believes it is the service encounter which is the determinant factor. O'Neill and Palmer (2004) also hold the exact same idea that, although tangibility is ranked as the best in term of overall performance score, but it has been ranked as the least importance by the students compared to process and empathy. Study by Perisau and McDaniel (1996) is best described as, assurance and reliability has been identified as the most important suggesting that students are most concern with the knowledge, courtesy and ability to inspire trust and confidence which is part of the assurance dimension.

While Ford, Joseph and Joseph (1999) go a little bit more specific on the services in their study about service quality by comparing the importance score of service quality in higher education for the New Zealand student sample and the United States sample. They found that for the New Zealand sample, academic reputation has been ranked as the first followed by career opportunities, programme issues, cost/time, physical aspects, location and others while for the USA sample, it was found that the first rank is academic reputation, cost/time, programme issues, others, physical aspects and choice influences. 


\subsection{Service Quality and Students Satisfaction}

Service Quality is considered as a critical prerequisite for establishing and sustaining satisfying relationship with valued customers. In this way, the association between service quality and customer satisfaction has emerged as a topic of significant and strategic concern (Cronin and Taylor, 1992). In general, perceived service quality is an antecedent to satisfaction (Spreng and Mckoy, 1996).

Bigne, Moliner and Sanchez (2003) found that the overall service quality have a significant relationship with satisfaction at $\mathrm{R}=0.66$. Han and Hayduk (2003) have confirmed that, even in the higher educational settings, there is a positive correlation between perception of service quality and student satisfaction, and analyzing upon the relationship based on each of the dimension of service quality, reliability $(\mathrm{R}=0.547$; sig. $=0.000)$ has the strongest relationship followed by responsiveness and empathy $(\mathrm{R}=0.5431$; sig. $=0.000)$, assurance $(\mathrm{R}=0.492$; sig. $=0.000)$ and tangibility $(\mathrm{R}=0.423$; sig. $=0.000)$.

Elliot and Shin (2002) found that the highly significant variables in the model that appear to directly impact overall customer satisfaction with university performance are:(1) excellence of instruction in major $(0.0522 ; \mathrm{p}<0.0002)$, (2) able to get desired classes $(0.0935 ; \mathrm{p}$ $<0.0000), \quad$ (3) knowledgeable advisor (0.0517; p < 0.0000), (4) knowledgeable faculty $(0.0406 ; \mathrm{p}<$ $0.0094),(5)$ overall quality of instruction $(0.0510 ; \mathrm{p}<0.0000),(6)$ tuition paid is a worthwhile.

\section{Methodology 3.1 Research Framework}

The researcher developed a model in Figure 3.1 to conceptualize the theoretical framework of the study. The model shows the dimensions of the service quality in university education from students' perspective and the factors that would influence the evaluation of service quality.

FIGURE 3.1: Conceptual Model for Service Delivery in Higher Education Ind. Variables Dep. Variable

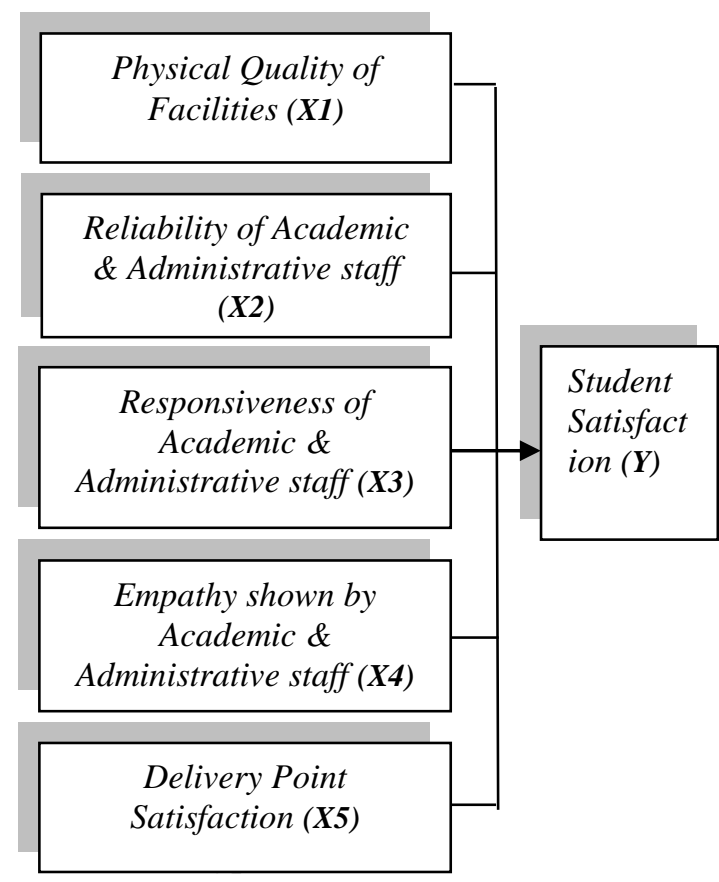

This study investigated five hypotheses as follows.

H1: Larger the extent of physical quality of facilitiesat the service delivery points at the university, greater the extent of students' satisfaction.

H2: Higher the degree of reliabilityof the services rendered by the academic and administrative staff, larger the extent of students' satisfaction. 
H3: Higher the degree of responsiveness of academic and administrative staffs of universities, larger the extent of student' satisfaction.

H4: Higher the degree of empathy has shown by academic and administrative staff, larger the extent of students' satisfaction.

H5: Higher the degree of service delivery point satisfaction of universities, larger the extent of students' satisfaction

\subsection{Sample}

In this study, the simple random sampling procedure was used. The sampling frame used in this study included all undergraduate students registered in the Rajarata University of Sri Lanka (RUSL), Sabaragamuwa University of Sri Lanka (SUSL), and Wayamba University of Sri Lanka (WUSL). The researcher selected 260 undergraduate students as the sample.

\subsection{Instrumentation}

This study used questionnaire as a medium to obtain the data needed. There were two sections in the questionnaire, consisting Part A: Demographic factors, Part B: Measurement in Service Quality in Higher Education. In this part A, four questions covering from the subjects of University of studying, gender, Ethnicity and year of studying. Part B covered service quality in higher education.

\subsection{Data Analysis Procedures}

This research used Pearson Correlation and Regression Analysis. The data analysis for this study conducted through "Statistical Package for Social Sciences' software or SPSS version 16. The study also tested reliability of the instrument so that it enables to produce a robust and valid result.

\section{Findings and Discussion}

Total of 260 students had responded and $68 \%$ trom WUSL, $16 \%$ from RUSL and $16 \%$ from SUSL. From the respondents are $71 \%$ female and $29 \%$ male. Most of the students are Sinhala (97\%) and Tamils and Muslims are $1.5 \%$ respectively. Meanwhile, year of studying the majority of them were second year (69\%), $28 \%$ in third year and $3 \%$ in fourth year.

The findings for physical quality of facilities show that mean is equal to -0.6. This means that most of students do not agree with physical quality of facilities available in the newish universities.

The mean for reliability is -0.16 and this explains students do not agree with reliability of services provided by the newish universities.

The mean for responsiveness is -0.34 and this explains students do not agree with responsiveness of services provided by the newish universities.

The mean for empathy is -0.27 and this explains students do not agree with empathy shown by administrative and academic staff of the newish universities. The mean for delivery point satisfaction is 0.16 and this explains students agree with delivery point satisfaction of services provided by the newish universities.

Hypothesis 1: Larger the extent of physical quality of facilities at the service delivery points at the university, greater the extent of students' satisfaction.

The relationship between Quality of physical facilities and student satisfaction was investigated using Pearson correlation coefficient. The results in Table 1 indicates, positive relationship between Quality of physical facilities and 
student satisfaction exists among students $(\mathrm{R}$ Square $=.154, \mathrm{n}=260, \mathrm{p}<.01)$.

Table 1: The Relationship between Quality of Physical facilities and Student Satisfaction

\begin{tabular}{|c|c|c|c|c|}
\hline $\begin{array}{l}\overline{0} \\
\bar{\delta} \\
\sum\end{array}$ & $\simeq$ & $\begin{array}{l}\mathscr{J} \\
\vec{\Xi} \\
\tilde{E} \\
\widetilde{L}\end{array}$ & 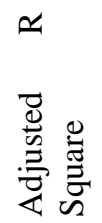 & 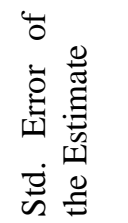 \\
\hline 1 & $.396(a)$ & .157 & .154 & 4.85366 \\
\hline
\end{tabular}

a. Predictors: (Constant), Qty. of Physical facilities

Hypothesis 2: Higher the degree of reliability of the services rendered by the academic and administrative staff, larger the extent of students' satisfaction.

Meanwhile Table 2 shows the relationship between Reliability and student satisfaction. The results in Table 2 indicates that positive relationship between Reliability and student satisfaction ( $\mathrm{R}$ Square .079, $\mathrm{n}=260$, $\mathrm{p}<.01)$

Table 2: The Relationship between Reliability and Student Satisfaction

\begin{tabular}{|c|c|c|c|c|}
\hline$\frac{\bar{d}}{\overline{0}}$ & $\mathscr{L}$ & $\begin{array}{l}\mathscr{\Xi} \\
\tilde{\Xi} \\
\tilde{E} \\
\underline{\mathscr{E}}\end{array}$ & 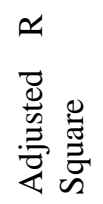 & 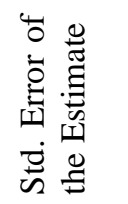 \\
\hline 1 & $.287(a)$ & .082 & .079 & 5.06495 \\
\hline
\end{tabular}

a. Predictors: (Constant), Reliability

Hypothesis 3: Higher the degree of responsiveness of academic and administrative staffs of universities, larger the extent of student' satisfaction.

The relationship between Responsiveness and students satisfaction was investigated and results in Table 3 indicates a positive relationship between two variables $(\mathrm{R}$ Square $=.079, \mathrm{n}=260, \mathrm{p}<.01)$.
Table 3: The Relationship between Responsiveness and Student Satisfaction

\begin{tabular}{|c|c|c|c|c|}
\hline $\begin{array}{l}\overline{0} \\
\frac{0}{2}\end{array}$ & $\simeq$ & 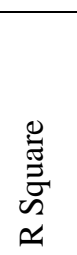 & 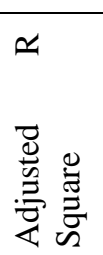 & 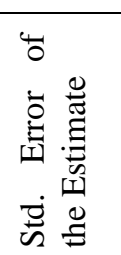 \\
\hline 1 & .319 (a) & .102 & .098 & 5.01075 \\
\hline
\end{tabular}

a. Predictors: (Constant), Responsiveness

Hypothesis 4: Higher the degree of empathy has shown by academic and administrative staff, larger the extent of students' satisfaction.

Meanwhile Table 4 shows the relationship between Empathy and students satisfaction and positive relationship between two variables ( $R$ Square $=.043, \mathrm{n}=260, \mathrm{p}<.01$ ).

Table 4: The Relationship between empathy and Student Satisfaction

\begin{tabular}{|c|c|c|c|c|}
\hline $\begin{array}{l}\bar{\nabla} \\
\bar{\delta}\end{array}$ & $\simeq$ & $\begin{array}{l}\tilde{\Xi} \\
\tilde{\Xi} \\
\mathscr{E} \\
\underline{\mathscr{L}}\end{array}$ & 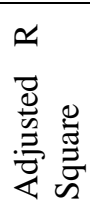 & 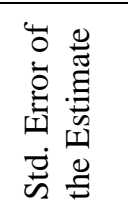 \\
\hline 1 & $.216(a)$ & .047 & .043 & 5.16235 \\
\hline
\end{tabular}

a. Predictors: (Constant), Empathy

Hypothesis 5: Higher the degree of service delivery point satisfaction of universities, larger the extent of students' satisfaction

The results in Table 5 indicates that a positive relationship between Delivery point satisfaction and students satisfaction $(\mathrm{R}$ Square $=.154, \quad \mathrm{n}=260$, $\mathrm{p}<.01)$. 
Table 5: The Relationship between Service delivery point satisfaction and Student Satisfaction

\begin{tabular}{|c|c|c|c|c|}
\hline $\begin{array}{l}\overline{0} \\
\overline{8} \\
\end{array}$ & $\simeq$ & 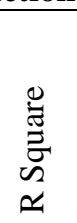 & 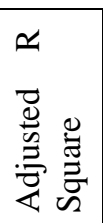 & 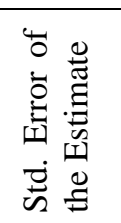 \\
\hline 1 & $.396(a)$ & .157 & .154 & 4.85366 \\
\hline
\end{tabular}

a. Predictors: (Constant), Ser. Del. Point.

\section{Conclusion}

Determining and assessing students' satisfaction is not easy, but can be very helpful for the universities to build strong relationship with their existing and potential students.

Research question 1 indicates that five service quality dimension has moderate relationship with students' satisfaction.

In the study, quality of physical facilities $(r=0.396)$ has the moderate relationship followed by service delivery point satisfaction $(\mathrm{r}=0.367)$, responsiveness $(\mathrm{r}=0.319)$, reliability $(\mathrm{r}=0.287)$ and empathy $(\mathrm{r}=0.216)$.

Seeing that quality of physical facilities has a stronger relationship than responsiveness and reliability bring the researcher back to what Umbach and Porter (2002) have been stressing on earlier, seeing it as a compliment to the services provided in higher education in such to enhance satisfaction. It was found that, although the dimensions in service quality are important but assurance is found to be one of the most important (Perisau and McDaniel, 1996).

In this study, the research question 2 indicates that quality of physical facilities $(\mathrm{B}=0.6555)$, reliability $(\mathrm{B}=0.489)$, and responsiveness $\quad(\mathrm{B}=0.471) \quad$ are significantly related with student satisfaction.
The results indicated that students have a positive relationship with depending variable.

Furthermore, the results of the study declared that the areas of service quality/delivery by the newish universities do not fulfil the requirements of the students.

The results also indicate that generally students are not satisfied with the service quality/delivery performed by the newish universities in Sri Lanka.

\section{References}

Berry, L. and Parasuraman, A. (1992). Perception for service quality. American Organizational Dynamics, 20 (4), 05-15.

Bigne, E., Moliner, M.A., and Sanchez, J. (2003). Perceived quality and satisfaction in multi service organizations: The case of Spanish public services. The Journal of Services Marketing, 17 (4), 420442.

Cronin, J.J. Jr., and Taylor, S.A. (1992). Measuring service quality: a reexamination and extension. Journal of Marketing, 56, 55-68.

Cuthbert, P.F (1996). Managing service quality in HE: is SERVQUAL The answer? Part 2. Managing Service Quality, 6(3), 31-35.

Dotchin, J.A. and Oakland, J.S., (1984). Total quality management in services-Part I: Understanding and classifying services. International Journal of Quality and Reliability Management, 11 (03), 9-43.

Elliot, K. M. and Shin, D. (2002). Student satisfaction: An alternative approach to assessing this 
important concept. Journal of Higher Education Policy and Management, 24 (2), 197 - 209.

Ford, J.B., Joseph, M, and Joseph, B. (1999). Importance-performance analysis as strategic tool for service marketers: The case of service quality perceptions of business students in New Zealand and the USA. The Journal of Services Marketing, 13(2), 171186.

Ghobadian, A., Speller, S., and Jores, M., (1994). Service quality: Concepts and models. International Journal of Quality and Reliability Management, 11(9), 43-66.

Gronroos, C., (1978). A service oriented approach to marketing of service. European Journal of Marketing, $12(8)$,

Ham, L., and Hayduk, S. (2003). Gaming competitive advantages in higher education: Analysis the gap between expectations and perceptions of service quality. International Journal of ValueBased Management. 16(3), 223242.

Kotler, P. and Clarke, R.N. (1987). Marketing for health care organizations, Englewood Cliffs, NJ: Prentice-Hall.

Lehtinen, U and Lehtinen, J.R. (1992). Service Quality: A Study of Quality Dimensions, Working paper, Service Management Institute, Helsinki.

O'Neill, M.A., and Palmer, A. (2004). Importance-performance Analysis:
A useful tool for directing continuous quality improvement in higher education. Quality Assurance in Education, 12(1), 39 -52 .

Parasuraman, A., Zeithaml, V.A and Berry, L.L. (1985). A conceptual model of service quality and Its Implications for future research. Journal of Marketing, 4 (4), 41-50.

Parasuraman, A., Zeithaml, V.A and Berry, L.L. (1988). SERVQUAL: A multiple-Item scale for measuring consumer perceptions of service quality. Journal of Retailing, 64 (1), 12-40.

Pevisau, S.E., and McDaniel, J.R (1996). Assessing service quality in schools of business. International Journal of Quality and Reliability Management, 14(3), 204-218.

Spreng, R.A. and Mackoy, R.D. (1996). An empirical examination of a model of perceived service quality and satisfaction. Journal of Retailing, 72(2), 52-64.

Umbach, P.D. and Porter, S.R. (2002). How do academic departments impact student satisfaction? Understanding the contextual effects of departments. Research in Higher Education, 43(2), 209234.

Zimmerman, C.D., and Enell, J.W.(1988). Service Industries", in Juran, J. and Gryna, J.M.(Eds.), Juran's Quality Control Handbook, $4^{\text {th }}$ ed, McGraw Hill, New York, NY. 